\title{
Optimism and consent to treatment
}

\author{
Fiona Godlee editor in chief, The BMJ
}

We know that patients and doctors tend to overestimate the benefits of treatment and underestimate the harms. We also know that people's natural optimism is often boosted by the systematic optimism bias of the medical literature (Br J Psych 2010;197:441-7, doi:10.1192/bjp.bp.110.078006; PLoS One 2014;9(5):e98246, doi:10.1371/journal.pone.0098246). But in the case of percutaneous coronary intervention there is no such excuse. Experts and guidelines are clear: it improves symptoms but not survival. Nor does it reduce the risk of myocardial infarction. It should be offered to patients with stable coronary artery disease only if medical treatment is failing to manage their angina.

Despite this clarity, Faraz Kureshi and colleagues confirm that patients still believe that it will do more than just control their symptoms (BMJ 2014;349:g5309, doi:10.1136/bmj.g5309). Of about 1000 patients surveyed, the vast majority thought that the procedure would extend or save their lives and would prevent myocardial infarction. Only $1 \%$ correctly reported that relief of symptoms was the only expected benefit.

Efforts to improve informed participation of patients in decision making are clearly failing. In what I believe is our first editorial coauthored by patients, Jeff Whittle and colleagues ask why this might be (BMJ 2014;349:g5613, doi:10.1136/bmj.g5613). The three coauthor patients all have personal or family experience of coronary revascularisation. Their views may prompt new thinking. One recalled that, although there was no statement that the procedure would prolong life, he sensed that the surgeon thought it would. Another was made aware of the seriousness of his condition and congratulated on its early discovery, which perhaps suggested that intervention would change the course of the disease. A third noted that having lots of time for questions doesn't help if the patient doesn't know which questions to ask.

Our editorialists consider what they acknowledge might be considered a heretical question: does it matter if patients don't have an entirely accurate understanding of the benefits of treatment? They conclude that it may not-and they even say that insisting that patients understand that treatment won't prolong life may be demoralising.

Some of us may find this hard to swallow. What of the risks of overtreatment based on unrealistic expectations? In their study Kureshi and colleagues found that patients' level of understanding varied between the 10 different sites and that the informed consent procedures differed. It may take only a few words to give a patient a false impression of what they can expect from a procedure.

I'm reminded of one of Daniel Sokol's recent columns (BMJ 2014;348:g2192, doi:10.1136/bmj.g2192). Consent should not be something we do to patients, he said. It should be seen more as a unique gold coin. "The clinician should not snatch it away, abruptly, deceptively, or without careful explanation. He or she should explain why the patient may wish to hand over the coin. What will the patient get in return? What if the patient wishes to keep it? Explaining all this can take time and skill. It is a two way process, but ultimately the decision remains with the patient."

Cite this as: BMJ 2014;349:g6118

๑ BMJ Publishing Group Ltd 2014 